\title{
Get Involved: Megan Frary, Material Advantage Advisor
}

\section{Kelly Zappas}

"Get Involved" is a recurring End Notes feature that spotlights the work of TMS volunteers and shows the wide range of activities available through TMS. This month, Megan Frary, an associate professor of materials science and engineering at Boise State University, discusses the challenges and opportunities that come with serving as an advisor to the Material Advantage student chapter at her school. Frary has been a faculty member at Boise State since 2005.

Q. How did you get involved with the Material Advantage chapter on your campus? Did you volunteer to serve as advisor or were you asked to step into the role?

A. I've been involved with the Material Advantage chapter since its beginning. When I arrived on campus, our department was only a year old, and there was no student group in the department. In my first year, I worked with the students to found a student club, which became an official Material Advantage chapter in 2007.

Q. How long have you been working as an advisor?

A. I've been advising the student club for about five and a half years.

Q. What kind of work is involved in advising a student chapter? Does it require a large time commitment?

A. The students do most of the work, which makes my job as advisor easier. I meet occasionally with the officers to help them brainstorm activities, and I'm present at the meetings to help keep things on track. Being a chapter advisor requires a small time commitment, but it's a great way to be able to interact with students outside the classroom.

Q. What is the most rewarding aspect of volunteering with the Material Advantage program?
A. The most rewarding aspect of volunteering with the Material Advantage program is seeing the students become more engaged with their classmates, with the department, and with the discipline. In each of the last three years, we've taken at least half a dozen Material Advantage members to the TMS annual meetings. The students work as session monitors, participate in the Materials Bowl, and have fun exploring a new city. It's great to talk with them when we get back and to hear about what an impact that experience had on them. We're looking forward to San Diego this spring!

Q. How can TMS members outside of academia volunteer to help with students?

A. We'd love to have more involvement with our Material Advantage chapter from TMS members outside of academia. Our students always want to know, "What can I do with a degree in materials science?" I think

If you want to get involved with your local Material Advantage student chapter, contact Deborah Price, TMS student affairs and awards administrator, at price@tms. org. She can help to connect you with a Material Advantage chapter near you. For more on the Material Advantage program, visit materialadvantage.org. If you know of a TMS member who should be featured in a future "Get Involved" column, contact Kelly Zappas at kzappas@tms.org.

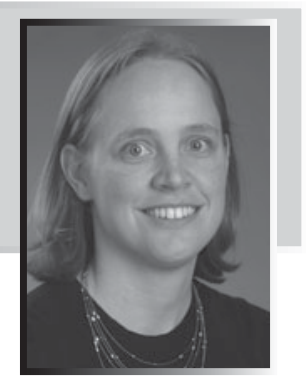

TMS members can play a valuable role here. There are very few TMS members in the Boise area not affiliated with the university. If there were, I imagine our students might like to tour a company's facilities or hear from a TMS member about their experiences in industry.

Q. In addition to serving as a student chapter advisor, do you participate in other volunteer activities with TMS as well?

A. I am a member of the TMS Women in Materials Science and Engineering Committee and a Key Reader for Metallurgical and Materials Transactions. I also try to attend one technical committee meeting each year at the TMS Annual Meeting.

Q. How do you balance your volunteer work with your full-time job?

A. Balancing volunteer activities with the rest of my job isn't too difficult. Our department has a strong focus on our undergraduate students, so my role as Material Advantage chapter advisor is part of creating the department culture we want to provide for our students.

Kelly Zappas is a contributing writer for JOM. 